\title{
Interceptação da radiação luminosa pelo dossel de espécies florestais e sua relação com o manejo das plantas daninhas
}

\author{
Interception of radiation by the canopy of forest species and its relationship with the weed \\ control requirement
}

\author{
Braulio Otomar Caron ${ }^{\mathrm{I}^{*}}$ Velci Queiróz de Souza ${ }^{\mathrm{II}}$ Ervandil Corrêa Costa ${ }^{\mathrm{III}}$ \\ Elder Eloy ${ }^{\mathrm{I}}$ Alexandre Behling ${ }^{\mathrm{I}}$ Rômulo Trevisan ${ }^{\mathrm{IV}}$
}

\section{RESUMO}

\begin{abstract}
A energia da radiação solar absorvida pelas plantas é fator determinante da taxa fotossintética e pode limitar a produção, o acúmulo de biomassa e o desenvolvimento das plantas. $O$ objetivo do trabalho foi avaliar a interceptação da radiação luminosa e sua relação com a necessidade de manejo de plantas daninhas através de coroamento e roçada, nas espécies florestais: Acacia mearnsii De Wild, Eucalyptus grandis W. Hill ex Maiden, Mimosa scabrella Benth e Ateleia glazioviana Baill, nos espaçamentos: 2,0x1,0m; 2,0x1,5m;3,0x1,0m e $3,0 \times 1,5 \mathrm{~m}$. A medição da radiação luminosa foi realizada mensalmente durante o período de 0 a 360 dias após o plantio. Os pontos de amostragens foram entre as plantas na linha e na entre-linha de plantio. O coroamento e a roçada não foram necessários quando os níveis de interceptação de radiação fotossinteticamente ativa foram maiores que $60 \%$. Porém, tornaram-se necessários a partir do segundo mês após o plantio e com frequência de 60 dias para todas as espécies até os primeiros 180 dias. $O$ coroamento foi dispensado para a espécie E. grandis a partir dos 210 dias e para A. mearnsii e M. scabrella após os 240 dias após o transplante. A roçada foi dispensada somente para a espécie $\boldsymbol{E}$. grandis nos espaçamentos 2,0x1,0m e 2,0x1,5m a partir dos 210 e 240 dias após o plantio, respectivamente.
\end{abstract}

Palavras chave: densidade de plantio, atividade silvicultural, competição por luz.

\section{ABSTRACT}

The energy of solar radiation absorbed by the plants is a decisive factor of the photosynthesis tax and it can limit the production, the biomass accumulation and the development of the plants. The objective of the research was to evaluate the interception of the luminous radiation and her relationship with the need of handling undesirable plants through crowning and mowing, in the forest species: Acacia mearnsii De Wild, Eucalyptus grandis W. Hill ex Maiden, Mimosa scabrella Benth e Ateleia glazioviana Baill, submitted at levels spacing: 2,0x1,0m;2,0x1,5m;3,0x1,0m and 3,0x1,5m. The measurement of the luminous radiation was accomplished monthly during the period from 0 to 360 days after the planting. The points of samplings were among the plants in the line and in the planting among-line. The crowning and mowing were not necessary when the levels of interception of radiation photosynthesis activate were larger than $60 \%$. However, they became necessary starting from the second month after the planting and with a frequency of 60 days for all the species until the first 180 days. The crowning was spared for the species E. grandis starting from the 210 days and for A. mearnsii and M. scabrella after the 240 days after the transplant. Cleared was given only for the species $\boldsymbol{E}$. grandis in the spacings 2,0x1,0m and 2,0x1,5m starting from the 210 and 240 days after the planting, respectively.

Key words: planting density, activity forestry, competition for light.

\section{INTRODUÇÃO}

Através dos avanços tecnológicos conquistados, tanto na área de conversão de matéria prima em energia, a partir de biomassa florestal, quanto nas atividades silviculturais brasileira, é possível

'Departamento de Agroclimatologia, Centro de Educação Superior Norte do Rio Grande do Sul (CESNORS), Universidade Federal de Santa Maria (UFSM), 98400-000, Frederico Westphalen, RS, Brasil. E-mail: braulio.caron@pq.cnpq.br. *Autor para correspondência. IIDepartamento de Melhoramento Genético de Plantas, CESNORS, UFSM, Frederico Westphalen, RS, Brasil.

"IIDepartamento de Defesa Fitossanitária, Centro de Ciências Rurais (CCR), UFSM, Santa Maria, RS, Brasil.

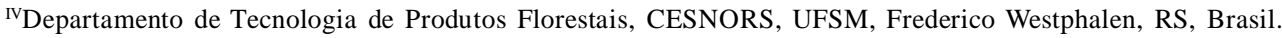


vislumbrar um cenário favorável ao desenvolvimento de florestas para fins energéticos em um espaço de tempo reduzido. A utilização dessa biomassa como insumo energético é uma tendência mundial e a motivação vem da necessidade de se reduzir a utilização de derivados de fontes fósseis, para que se possam reduzir as emissões de gases nocivos na atmosfera.

A competição com plantas daninhas é um fator limitante à sobrevivência e ao crescimento da maioria das espécies florestais. PITELLI \& MARCHI (1991) citam que a interferência imposta pela matocompetição é mais severa principalmente na fase inicial de crescimento. Árvores que se desenvolvem sobinterferência de plantas daninhas podem apresentar deficiência de nutrientes essenciais, resultado da competição imposta pela comunidade infestante (MARCHI et al., 1995). Dentre as operações florestais e tratos culturais que mais necessitam de mão de obra, encontra-se a roçada e o coroamento, aplicadas no controle de plantas daninhas, representando uma parte significativa do investimento no estabelecimento do povoamento (AMBIENTE BRASIL, 2009). SILVA et al. (2004), avaliando os custos de produção e os tempos gastos nas etapas de produção de mudas, preparo do solo, plantio e tratos culturais de um plantio de eucalipto em região de cerrado, observaram que os maiores tempos consumidos foram durante a capina do povoamento e plantio, correspondendo a $27 \%$ e $22 \%$, respectivamente. De acordo com TOLEDO (2003), a maior incidência da matocompetição em plantações de eucalipto ocorre até o 7o mês após o plantio.

Os tratos culturais são indispensáveis na fase de estabelecimento do povoamento florestal e têm como objetivo eliminar a matocompetição (AMBIENTE BRASIL, 2009). Nesse sentido, para o adequado controle da interferência de plantas daninhas em reflorestamentos, é importante conhecer a época em que elas mais competem com a cultura. Durante essa fase, as capinas e roçadas devem ser realizadas sempre que necessário. A energia de radiação solar absorvida pelas plantas é fator determinante da taxa fotossintética e pode limitar a produção e o acúmulo de biomassa e, consequentemente, o desenvolvimento das plantas (CARON et al., 2003; PILAU, 2005). Alguns fatores complementares como temperatura do ar e do solo, a nutrição mineral, a disponibilidade hídrica e condições para uma maior absorção adequada de $\mathrm{CO}$ também podem condicionar o crescimento, desenvolvíimento e produtividade das espécies.

A influência das condições ambientais está diretamente relacionada com a eficiência do desenvolvimento das plantas, principalmente a radiação solar global incidente e a temperatura do ar (CARON et al., 2003). O conhecimento da interceptação da radiação luminosa pela copa das árvores sob espaçamentos variados permite ao silvicultor avaliar a necessidade e o planejamento adequados de intervenções, tais como roçadas, capinas ou uso de produtos químicos, possibilitando o melhor aproveitamento desses recursos. Nos espaçamentos menores, devido à rápida formação do dossel, a necessidade de tratos culturais é menor quando comparadas aos espaçamentos maiores (AMBIENTE BRASIL, 2009). Esse fato também está relacionado com a disponibilidade de radiação luminosa, já que a quantidade dessa variável meteorológica para as plantas daninhas é diminuída, à medida que ocorre o fechamento do dossel pela cultura.

Nesse contexto, o objetivo dessa pesquisa foi avaliar a interceptação da radiação luminosa através do dossel de quatro espécies florestais, submetidas a quatro espaçamentos, e sua relação com as atividades de coroamento e roçada, utilizadas no controle das plantas daninhas.

\section{MATERIAL E MÉTODOS}

O trabalho foi realizado tendo como base o experimento, que está localizado em uma área pertencente à Universidade Federal de Santa Maria, coordenadas geográficas $27^{\circ} 22^{\prime \prime} \mathrm{S} ; 53^{\circ} 25^{\prime}$ W, a $480 \mathrm{~m}$ de altitude, município de Frederico Westphalen - RS. Segundo a classificação climática de Köppen, o clima da região é $\mathrm{Cfa}$, ou seja, subtropical úmido com temperatura média anual de $19,1^{\circ} \mathrm{C}$, variando com máxima de 38 e mínimo de $0^{\circ} \mathrm{C}$, apresentando uma precipitação média anual de $1606 \mathrm{~mm}$. O solo da área experimental é do tipo Latossolo Vermelho distrófico típicoe, no seu preparo para o plantio das mudas, foram realizadas as operações de aração e gradagem. O plantio foi feito de forma manual, com posterior adubação recomendada para cada espécie, sendo a direção do plantio perpendicular ao sentido da luz do sol.

Odelineamento experimental utilizado foi em blocos completos casualizados com três repetições, em arranjo fatorial $4 \times 4$, sendo quatro espécies florestais (Acacia mearnsii De Wild, Eucalyptus grandis W. Hill ex Maiden, Mimosa scabrella Benth e Ateleia glazioviana Baill) e quatro espaçamentos $(2,0 \times 1,0 \mathrm{~m}$, 2,0x 1,5m, 3,0x1,0m e 3,0x1,5m). O bloco contempla 16 parcelas experimentais, sendo que cada uma possui 45 plantas distribuídas em cinco linhas.

A necessidade do manejo das plantas daninhas foi determinada mediante o julgamento de dois Engenheiros Florestais, dois Engenheiros Agrônomos, um Técnico Florestal e um Acadêmico do curso de Engenharia Florestal, simultaneamente em todas as avaliações, doze meses após o plantio. Os parâmetros utilizados no julgamento da necessidade de manejo das plantas daninhas foram denominados: 
classe 1: Sem necessidade de manejo (plantas daninhas em baixo número ou inexistentes); classe 2: Futura necessidade de manejo (plantas daninhas presentes, porém competindo com as árvores a um nível muito baixo, a ponto de não causar prejuízos a curto prazo); e classe 3: Há necessidade de manejo (plantas daninhas competindo com as árvores).

O manejo das plantas daninhas foi realizado por meio de coroamento e roçada, na linha e na entrelinha de plantio, utilizando-se enxada e roçadeira costal, respectivamente, sempre que o julgamento atingiu o nível 3. A avaliação da radiação luminosa foi tomada mensalmente em todas as unidades experimentais no período de 0 a 360 dias após o plantio das mudas. A medição foi realizada em duas posições entre as plantas: na linha, denominada de R1, que foi pertinente para se determinar a necessidade de coroamento, e na entrelinha de plantio, denominada de R2, que foi específica para caracterizar a necessidade de roçada. A determinação foi feita com um medidor acoplado a um quantômetro (LI-COR 1600) nas duas posições, utilizando-se a equação:

$\%$ interceptação $=\left[100-\left(R_{n} \times 100 / R_{t}\right)\right]$, em que: $R_{n}=$ radiação luminosa incidente em $\mathrm{R} 1$ ou $\mathrm{R} 2 ; \mathrm{R}_{\mathrm{t}}=$ radiação luminosa total incidente na parte superior do dossel.

Os valores obtidos na porcentagem de interceptação foram relacionados com os dados da tabela 1, através da correlação de Spearman. Na linha

Tabela 1 - Necessidade de coroamento (R1) e de roçada (R2) no período de 0 a 360 dias após o plantio (DAP) das espécies florestais $\boldsymbol{A}$. mearnsii, E. grandis, M. scabrella e A. glazioviana, submetidas a diferentes espaçamentos.

\begin{tabular}{|c|c|c|c|c|c|c|c|c|c|c|c|c|c|c|}
\hline \multirow{2}{*}{ Espécie } & \multirow{2}{*}{ Espaçamento (m) } & \\
\hline & & 0 & 30 & 60 & 90 & 120 & 150 & 180 & 210 & 240 & 270 & 300 & 330 & 360 \\
\hline \multicolumn{15}{|c|}{ Necessidade de coroamento (R1) } \\
\hline \multirow{4}{*}{ A. mearnsii } & $2,0 \times 1,0$ & 1 & 1 & 3 & 2 & 3 & 2 & 3 & 2 & 1 & 1 & 1 & 1 & 1 \\
\hline & $2,0 \times 1,5$ & 1 & 1 & 3 & 2 & 3 & 2 & 3 & 2 & 1 & 1 & 1 & 1 & 1 \\
\hline & $3,0 \times 1,0$ & 1 & 1 & 3 & 2 & 3 & 2 & 3 & 2 & 1 & 1 & 1 & 1 & 1 \\
\hline & $3,0 \times 1,5$ & 1 & 1 & 3 & 2 & 3 & 2 & 3 & 2 & 1 & 1 & 1 & 1 & 1 \\
\hline \multirow{4}{*}{ E. grandis } & $2,0 \times 1,0$ & 1 & 1 & 3 & 2 & 3 & 2 & 3 & 1 & 1 & 1 & 1 & 1 & 1 \\
\hline & $2,0 \times 1,5$ & 1 & 1 & 3 & 2 & 3 & 2 & 3 & 1 & 1 & 1 & 1 & 1 & 1 \\
\hline & $3,0 \times 1,0$ & 1 & 1 & 3 & 2 & 3 & 2 & 3 & 1 & 1 & 1 & 1 & 1 & 1 \\
\hline & $3,0 \times 1,5$ & 1 & 1 & 3 & 2 & 3 & 2 & 3 & 1 & 1 & 1 & 1 & 1 & 1 \\
\hline \multirow{4}{*}{ M. scabrella } & $2,0 \times 1,0$ & 1 & 1 & 3 & 2 & 3 & 2 & 3 & 2 & 1 & 1 & 1 & 1 & 1 \\
\hline & $2,0 \times 1,5$ & 1 & 1 & 3 & 2 & 3 & 2 & 3 & 2 & 1 & 1 & 1 & 1 & 1 \\
\hline & $3,0 \times 1,0$ & 1 & 1 & 3 & 2 & 3 & 2 & 3 & 2 & 1 & 1 & 1 & 1 & 1 \\
\hline & $3,0 \times 1,5$ & 1 & 1 & 3 & 2 & 3 & 2 & 3 & 2 & 1 & 1 & 1 & 1 & 1 \\
\hline \multirow{4}{*}{ A. glazioviana } & $2,0 \times 1,0$ & 1 & 1 & 3 & 2 & 3 & 2 & 3 & 2 & 2 & 3 & 2 & 2 & 3 \\
\hline & $2,0 \times 1,5$ & 1 & 1 & 3 & 2 & 3 & 2 & 3 & 2 & 2 & 3 & 2 & 2 & 3 \\
\hline & $3,0 \times 1,0$ & 1 & 1 & 3 & 2 & 3 & 2 & 3 & 2 & 2 & 3 & 2 & 2 & 3 \\
\hline & $3,0 \times 1,5$ & 1 & 1 & 3 & 2 & 3 & 2 & 3 & 2 & 2 & 3 & 2 & 2 & 3 \\
\hline & & & & Nece & lade & roçad & (R2) & -- & $---\cdot$ & 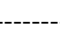 & --- & --- & $----\cdot$ & -- \\
\hline \multirow{4}{*}{ A. mearnsii } & $2,0 \times 1,0$ & 1 & 1 & 3 & 2 & 3 & 2 & 3 & 2 & 2 & 3 & 2 & 2 & 3 \\
\hline & $2,0 \times 1,5$ & 1 & 1 & 3 & 2 & 3 & 2 & 3 & 2 & 2 & 3 & 2 & 2 & 3 \\
\hline & $3,0 \times 1,0$ & 1 & 1 & 3 & 2 & 3 & 2 & 3 & 2 & 2 & 3 & 2 & 2 & 3 \\
\hline & $3,0 \times 1,5$ & 1 & 1 & 3 & 2 & 3 & 2 & 3 & 2 & 2 & 3 & 2 & 2 & 3 \\
\hline \multirow{4}{*}{ E. grandis } & $2,0 \times 1,0$ & 1 & 1 & 3 & 2 & 3 & 2 & 3 & 1 & 1 & 1 & 1 & 1 & 1 \\
\hline & $2,0 \times 1,5$ & 1 & 1 & 3 & 2 & 3 & 2 & 3 & 2 & 1 & 1 & 1 & 1 & 1 \\
\hline & $3,0 \times 1,0$ & 1 & 1 & 3 & 2 & 3 & 2 & 3 & 2 & 2 & 3 & 2 & 2 & 3 \\
\hline & $3,0 \times 1,5$ & 1 & 1 & 3 & 2 & 3 & 2 & 3 & 2 & 2 & 3 & 2 & 2 & 3 \\
\hline \multirow{4}{*}{ M. scabrella } & $2,0 \times 1,0$ & 1 & 1 & 3 & 2 & 3 & 2 & 3 & 2 & 2 & 3 & 2 & 2 & 3 \\
\hline & $2,0 \times 1,5$ & 1 & 1 & 3 & 2 & 3 & 2 & 3 & 2 & 2 & 3 & 2 & 2 & 3 \\
\hline & $3,0 \times 1,0$ & 1 & 1 & 3 & 2 & 3 & 2 & 3 & 2 & 2 & 3 & 2 & 2 & 3 \\
\hline & $3,0 \times 1,5$ & 1 & 1 & 3 & 2 & 3 & 2 & 3 & 2 & 2 & 3 & 2 & 2 & 3 \\
\hline \multirow{4}{*}{ A. glazioviana } & $2,0 \times 1,0$ & 1 & 1 & 3 & 2 & 3 & 2 & 3 & 2 & 2 & 3 & 2 & 2 & 3 \\
\hline & $2,0 \times 1,5$ & 1 & 1 & 3 & 2 & 3 & 2 & 3 & 2 & 2 & 3 & 2 & 2 & 3 \\
\hline & $3,0 \times 1,0$ & 1 & 1 & 3 & 2 & 3 & 2 & 3 & 2 & 2 & 3 & 2 & 2 & 3 \\
\hline & $3,0 \times 1,5$ & 1 & 1 & 3 & 2 & 3 & 2 & 3 & 2 & 2 & 3 & 2 & 2 & 3 \\
\hline
\end{tabular}


do plantio, as avaliações foram feitas na posição mediana entre as plantas, ou seja, a $0,5 \mathrm{~m}$ nos espaçamentos 2,0x1,0 e 3,0x1,0m; e a $0,75 \mathrm{~m}$ delas nos espaçamentos 2,0x1,5 e 3,0x1,5m. Na entre-linha de plantio, as medições foram feitas na posição mediana entre as linhas, ou seja, a 1,0m para os espaçamentos $2,0 \times 1,0 \mathrm{~m}$ e $2,0 \times 1,5 \mathrm{~m}$; e $1,5 \mathrm{~m}$ para os espaçamentos $3,0 \times 1,0 \mathrm{~m}$ e $3,0 \times 1,5 \mathrm{~m}$. Todas as leituras foram feitas a $0,15 \mathrm{~m}$ de altura. Os dados obtidos foram submetidos à análise estatística, através do software SAS Learning Edition 8.0 (2003), em que se testou a heterocedasticidade da variância e determinou-se a análise de variância, análise de regressão, teste $\mathrm{F}$ e o teste de Tukey a P>0,05.

Para caracterização e estudo da comunidade de plantas daninhas, foi utilizado como unidade amostral um quadro $(0,25 \times 0,25 \mathrm{~m})$, lançado aleatoriamente uma vez por parcela em dois blocos, em setembro de 2009. Em cada quadro amostrado, com o auxílio de um especialista, foram identificados e determinados os números de plantas presente de cada espécie. Para análise da comunidade das espécies, foram calculados os parâmetros fitossociológicos: frequência, densidade, abundância, frequência relativa, densidade relativa, abundância relativa e índice de valor de importância. O cálculo das características foi feito de acordo com as fórmulas de MUELLER-DOMBOIS \&ELLENBERG(1974).

\section{RESULTADOS E DISCUSSÃO}

A análise de variância apontou diferenças significativas na linha e na entre-linha para as variáveis dias após o plantio, espécie e na interação dias após o plantio $x$ espécie. Sendo que se observou diferença significativa somente para entre-linha, no espaçamento e nas interações dias após o plantio $x$ espaçamento e espécie $x$ espaçamento. Todas as espécies, a exceção da A. glazioviana, apresentaram diferença significativa após os 90DAP. Essa característica também foi observada para estas mesmas espécies nos quatro espaçamentos testados (Tabela 2).

As espécies florestais, com exceção da $\boldsymbol{A}$. glazioviana, apresentaram, no espaçamento 3,0x1,0m, as maiores médias de interceptação da radiação luminosa no sentido linha, quando comparadas com as outras densidades de plantio. Já na entre-linha, as maiores médias para $\boldsymbol{E}$. grandis e A. mearnsii prevaleceram no espaçamento $2,0 x 1,0 \mathrm{~m}$, e na $\boldsymbol{M}$. scabrella no 2,0x1,5m (Tabela 3). Quando analisada a correlação entre a radiação luminosa e a necessidade de manejo, observa-se uma correlação negativa $(-0,46)$, ou seja, à medida que aumenta a interceptação da radiação luminosa diminui a necessidade de manejo das plantas daninhas. Assim, conforme ocorre a formação do dossel das espécies florestais, observase aumento de interceptação de radiação solar, diminuindo a disponibilidade desse recurso às plantas daninhas, acarretando menor crescimento delas. É possível destacar que, quanto menor o espaçamento entre as plantas, mais cedo será dispensado o manejo, fato observado na tabela 1 e também relatado por AMBIENTE BRASIL (2009).

Até os 30 dias, não houve necessidade de coroamento ou roçada, pois as plantas daninhas foram eliminadas por ocasião do preparo do solo para o transplante das mudas. A necessidade de coroamento foi dispensada para a espécie $\boldsymbol{E}$. grandis passados 210 dias do plantio (Tabela 1). Já para A. mearnsii e $\boldsymbol{M}$. scabrella, foi dispensado a partir dos 240 dias. Isso se relaciona com a densidade de plantio das espécies florestais; logo o maior crescimento e o fechamento do dossel na linha de plantio reduzem as quantidades das plantas daninhas.

A espécie $\boldsymbol{A}$. glazioviana foi a única que não apresentou interceptação de radiação luminosa nas posições medidas. Essa característica observada está diretamente relacionada com o seu crescimento que é considerado lento a demorado, conforme CARVALHO (2003). Comparada às demais espécies, terá um período mais prolongado de manejo das plantas daninhas, tanto no coroamento quanto na roçada.

Nos meses de dezembro (90 dias) e fevereiro (150 dias), observou-se a necessidade futura do manejo das plantas daninhas, fato este relacionado ao manejo de coroamento e roçada ter sido realizado nos meses anteriores. Já nos meses de novembro (60 dias), janeiro (120 dias) e março (180 dias), observaram-se a necessidade de coroamento e roçada para todas as espécies e em todos os espaçamentos. Logo, percebese que, a partir do segundo mês após o plantio, o manejo das plantas infestantes deve ser realizado e frequente a cada 60 dias durante os seis primeiros meses.

Para a espécie $\boldsymbol{E}$. grandis, a roçada é dispensada nos espaçamentos 2,0x 1,0m e 2,0x1,5m aos 210 e 240 dias após o plantio (Tabela 1). Essa condição está relacionada ao rápido crescimento dessa espécie, proporcionando maior dossel e o consequente sombreamento do solo, reduzindo as plantas 
Tabela 2 - Análise de variância para a interceptação da radiação luminosa na linha e entre-linha das espécies florestais distribuídas nos diferentes espaçamentos, em diferentes dias após o plantio.

\begin{tabular}{|c|c|c|c|}
\hline \multicolumn{4}{|c|}{ Efeito principal } \\
\hline \multirow[t]{2}{*}{ Fator de estudo } & \multirow[t]{2}{*}{ Grau de liberdade } & \multicolumn{2}{|c|}{ 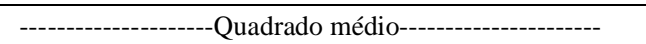 } \\
\hline & & Interceptação na linha & Interceptação na entre-linha \\
\hline DAP & 12 & $33313,95 *$ & $13213,08^{*}$ \\
\hline Espécie & 3 & $76020,22 *$ & $27379,22 *$ \\
\hline DAP $x$ espécie & 36 & $4164,63 *$ & $1840,34 *$ \\
\hline Espaçamento & 3 & $81,1^{\mathrm{ns}}$ & $1589,68^{*}$ \\
\hline DAP $x$ espaçamento & 36 & $27,48^{\mathrm{ns}}$ & $84,43 *$ \\
\hline Espécie $x$ espaçamento & 9 & $54,35^{\text {ns }}$ & $754,74 *$ \\
\hline DAP $x$ espécie $x$ espaçamento & 108 & $36,93^{\mathrm{ns}}$ & $78,66^{\mathrm{ns}}$ \\
\hline \multicolumn{2}{|c|}{ Coeficiente de determinação (\%) } & 97,98 & 98,35 \\
\hline \multicolumn{2}{|c|}{ Coeficiente de variação (\%) } & 19,09 & 18,68 \\
\hline \multirow{6}{*}{ Espécie } & A. mearnsii & $13617^{*}$ & $4582,61 *$ \\
\hline & M. scabrella & $14565^{*}$ & $5039,01 *$ \\
\hline & E. grandis & $17625^{*}$ & $9112,48^{*}$ \\
\hline & A. glazioviana & $1,01 \mathrm{e}-24^{\mathrm{ns}}$ & $2,01 \mathrm{e}-26^{\mathrm{ns}}$ \\
\hline & 0 & $1,16 \mathrm{E}-27^{\mathrm{ns}}$ & $2,08 \mathrm{e}-27^{\mathrm{ns}}$ \\
\hline & 30 & $1,28-26^{\mathrm{ns}}$ & $1,06 \mathrm{e}-26^{\mathrm{ns}}$ \\
\hline \multirow{11}{*}{ DAP } & 60 & $1,26-26^{\mathrm{ns}}$ & $5,60 \mathrm{e}-27^{\mathrm{ns}}$ \\
\hline & 90 & $167,28^{*}$ & $42,75^{*}$ \\
\hline & 120 & $650,80^{*}$ & $433,69^{*}$ \\
\hline & 150 & $1560,58 *$ & $828,69^{*}$ \\
\hline & 180 & $6211,02 *$ & $1408,5^{*}$ \\
\hline & 210 & $10169^{*}$ & $2821^{*}$ \\
\hline & 240 & $27622 *$ & $8759,38^{*}$ \\
\hline & 270 & $17317 *$ & $6052,85^{*}$ \\
\hline & 300 & $20227^{*}$ & $8659,69^{*}$ \\
\hline & 330 & $21506^{*}$ & $10702 *$ \\
\hline & 360 & $20565^{*}$ & $12655^{*}$ \\
\hline \multirow{4}{*}{ Espécie } & $\begin{array}{l}\text { A. mearnsii } \\
\text { - Espécie } x \mathrm{E}\end{array}$ & ---- & $149,04 *$ \\
\hline & M. scabrella & --- & $72,22 *$ \\
\hline & E. grandis & --- & $3632,64 *$ \\
\hline & A. glazioviana & --- & $1,79 e-27^{\text {ns }}$ \\
\hline \multirow{4}{*}{ Espaçamento } & $2 \times 1$ & --- & $10773 *$ \\
\hline & $2 \times 1,5$ & --- & $9833,92 *$ \\
\hline & $3,5 \times 1$ & --- & $4616,22 *$ \\
\hline & $3 \times 1,5$ & --- & $4420,53^{*}$ \\
\hline
\end{tabular}

$*=$ significativo a $5 \%$ de probabilidade; ${ }^{\text {ns }}=$ não significativo a $5 \%$ de probabilidade. $\mathrm{DAP}=$ Dias após o plantio.

infestantes. TOLEDO (2003) relata resultados semelhantes em plantações de eucalipto até o $7^{\circ}$ mês após o plantio. Após essa fase inicial, o eucalipto estará normalmente bem estabelecido e o fechamento das copas praticamente impedirá o crescimento das plantas daninhas (TAROUCO et al., 2009).

A menor interceptação de radiação luminosa para A. mearnsii, tanto na linha como na entre-linha, aos 360 dias após o plantio, está relacionada com a ocorrência de geada nos meses de junho e julho que ocasionou queda das folhas dessa espécie (Figura 1). Aos 120 dias, a interceptação na entre-linha foi maior nos espaçamentos 2,0x 1,0m e 2,0x 1,5m em relação aos demais (Figura 1). SCHNEIDER (2001) cita que o gênero Acacia tem característica de rápido crescimento e consequentemente maior desenvolvimento da cobertura arbórea.

Ciência Rural, v.42, n.1, jan, 2012. 
Tabela 3 - Interceptação da radiação luminosa na linha e na entre-linha das espécies florestais distribuídas nos diferentes espaçamentos, em diferentes dias após o plantio (DAP).

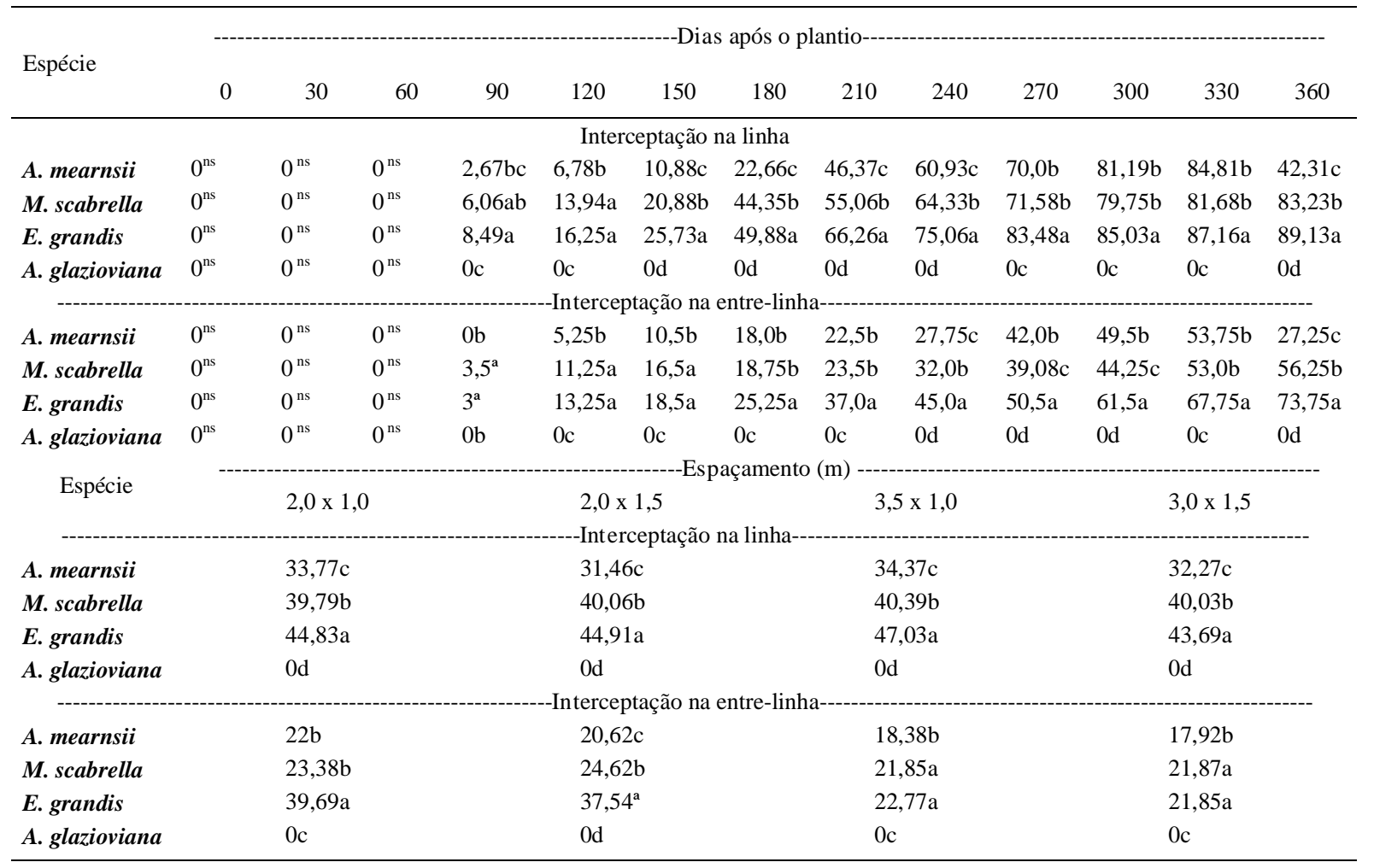

* = significativo a $5 \%$ de probabilidade; ${ }^{\text {ns }}=$ não significativo a $5 \%$ de probabilidade. $\mathrm{DAP}=$ Dias após o plantio.

Quando analisadas as plantas daninhas na área experimental, foram identificadas 10 espécies (Tabela 4) em que se observa a predominância de espécies da classe Magnoliopsidas, sendo Sida rhombifolia a mais infestante, com densidade equivalente a 62 plantas $\mathrm{m}^{-2}$, além de Lolium multiflorum e Commelina benghalensis da classe Liliopsidas. Essas espécies identificadas caracterizamse por infestar lavouras agrícolas e pastagens, causando dano quando nenhuma medida de manejo é adotada (BIANCO et al., 2008).

A principal espécie infestante nos tratamentos com A. mearnsii, M. scabrella e E. grandis foi S. rhombifolia com densidades de 66, 78 e 76 plantas $\mathrm{m}^{-2}$, respectivamente. Em sistemas florestais, o plantio de mudas no limpo, ou seja, sem a infestação de plantas daninhas favorece o estabelecimento da cultura e o monitoramento deve ser feito para evitar que as plantas daninhas afetem o crescimento das árvores (TUFFI
SANTOS et al., 2007). TAROUCO (2008) cita que a matocompetição em $\boldsymbol{E}$. grandis comprometeu o desenvolvimento da espécie, reduzindo a área foliar, o diâmetro de caule, a estatura de plantas e a matéria seca do caule, em um povoamento com espaçamento 3,5x2,0m, em Cerrito-RS. Dessa forma, estabeleceu que medidas de controle para plantas daninhas devem ser adotadas entre 107 e 129 dias após o transplante das mudas.

A distribuição das espécies daninhas variou quando a espécie florestal foi A. glazioviana (dados não mostrados). Para essa espécie cujo crescimento é mais lento, a planta infestante com maior densidade de infestação foi $S$. media, 46 plantas m $^{-2}$, a segunda mais ocorrente na área experimental, após $\boldsymbol{S}$. rhombifolia (Tabela 4). Esta planta é comumente encontrada em lavouras de inverno no Sul do Brasil como trigo, cevada e aveia (KISSMANN \& GROTH, 2000) e, possivelmente, desenvolveu-se melhor onde o solo ficou descoberto em função do lento crescimento de $\boldsymbol{A}$. glazioviana. 


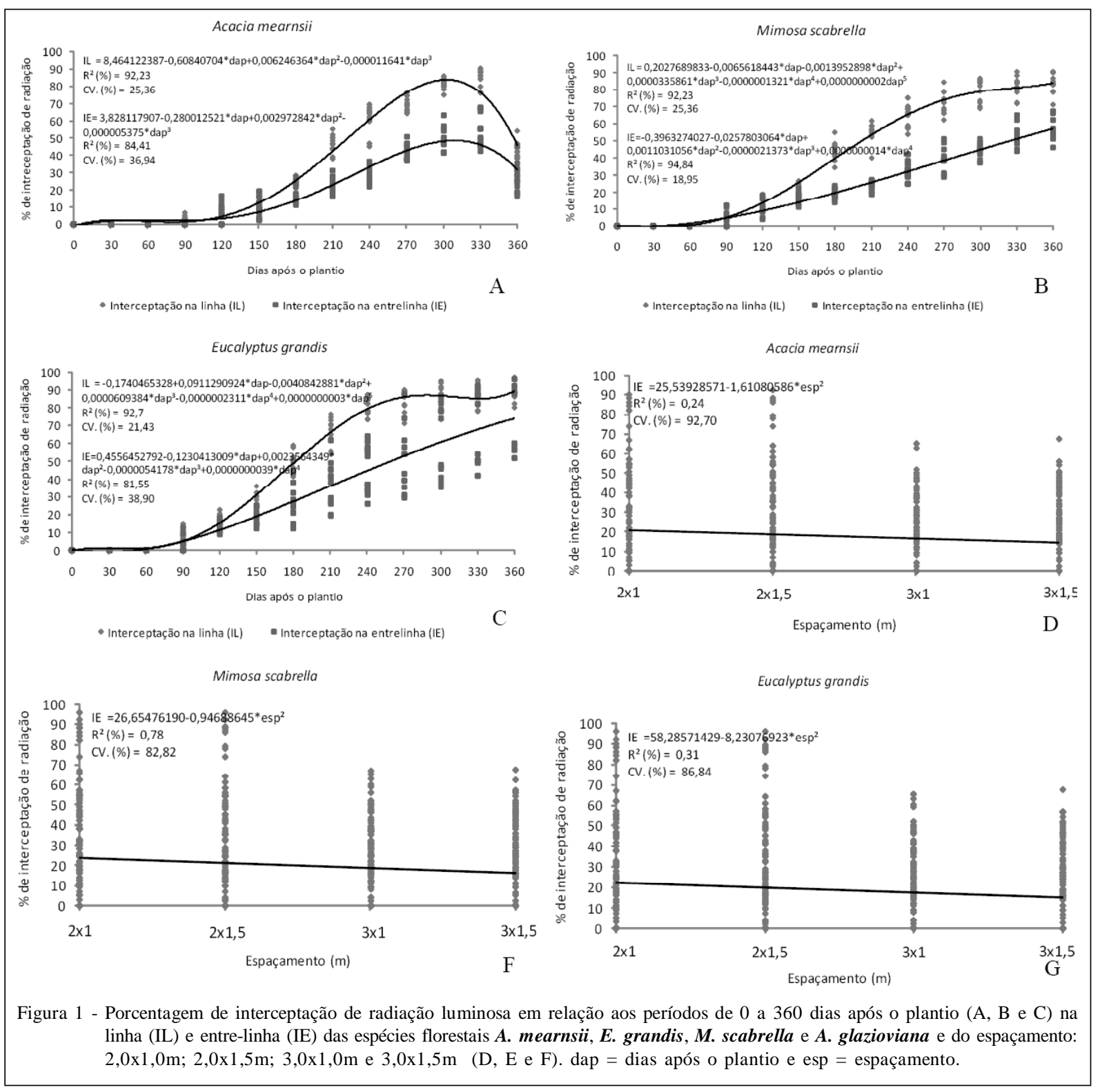

A presente pesquisa identificou as principais plantas daninhas na área experimental. Uma vez conhecido o potencial de interferência e dano dessas espécies aos plantios florestais, ressalta-se a importância da realização do manejo delas no momento mais correto.

\section{CONCLUSÃO}

O coroamento e a roçada não são necessários enquanto os níveis de interceptação de radiação luminosa forem superiores a $60 \%$. Tornam-se necessários a partir do segundo mês após o plantio e com frequência de 60 dias para todas as espécies durante os primeiros 180 dias. Após 210 dias do plantio, essa operação é dispensada para $\boldsymbol{E}$. grandis e, após 240 dias, para A. mearnsii e M. scabrella. As roçadas são dispensadas para $\boldsymbol{E}$. grandis nos espaçamentos $2,0 \times 1,0$ e 2,0x 1,5m a partir dos 210 e 240 dias após o plantio, respectivamente.

As principais plantas daninhas encontradas na área experimental foram $S$. rhombifolia e S. media, com as maiores densidades de infestação. A tomada de decisão para o manejo da matocompetição pode ser auxiliada com a utilização de valores da interceptação de radiação luminosa. 
Tabela 4 - Espécies daninhas ocorrentes na área experimental com as espécies florestais A. mearnsii, E. grandis, M. scabrella e $\boldsymbol{A}$. glazioviana, distribuídas em diferentes espaçamentos.

\begin{tabular}{|c|c|c|c|c|c|c|c|c|c|}
\hline Nome científico & Nome vulgar & Família botânica & FRE & DEN & $\mathrm{ABU}$ & FRR & DER & ABR & IVI \\
\hline Sida rhombifolia $\mathrm{L}$. & Guanxuma & Malvaceae & 0,75 & 62 & 5,2 & 24,24 & 27,8 & 7,35 & 59,4 \\
\hline Stellaria media (L.) Vill. & Esparguta & Caryophyllaceae & 0,37 & 28 & 4,7 & 12,12 & 12,55 & 6,64 & 31,32 \\
\hline Sonchus oleraceus L. & Serralha & Asteraceae & 0,37 & 16,5 & 2,8 & 12,12 & 7,3 & 3,91 & 23,43 \\
\hline Echium plantagineum $\mathrm{L}$. & flor-roxa & Boraginaceae & 0,06 & 10 & 10 & 2,02 & 4,48 & 14,23 & 20,73 \\
\hline Lolium multiflorum $\mathrm{L}$. & Azevém & Poaceae & 0,06 & 4 & 4 & 2,02 & 1,79 & 5,69 & 9,5 \\
\hline Commelina benghalensis L. & Trapoeraba & Commelinaceae & 0,06 & 3,5 & 3,5 & 2,02 & 1,57 & 4,98 & 8,57 \\
\hline Silene gallica $\mathrm{L}$. & alfinete-da-terra & Caryophyllaceae & 0,03 & 1,5 & 3 & 1,01 & 0,67 & 4,27 & 5,95 \\
\hline Spergula arvensis $\mathrm{L}$. & Gorga & Caryophyllaceae & 0,03 & 1 & 2 & 1,01 & 0,45 & 2,85 & 4,3 \\
\hline Chenopodium album $\mathrm{L}$. & ançarinha-branca & Chenopodiaceae & 0,03 & 0,5 & 1 & 1,01 & 0,22 & 1,42 & 2,66 \\
\hline Eryngium horridum Malme & Gravatá & Apiaceae & 0,03 & 0,5 & 1 & 1,01 & 0,22 & 1,42 & 2,66 \\
\hline
\end{tabular}

$\mathrm{FRE}=$ frequência, $\mathrm{DEN}=$ densidade, $\mathrm{ABU}=$ abundância, $\mathrm{DER}=$ densidade relativa, $\mathrm{FRR}=$ frequência relativa, $\mathrm{ABR}=$ abundância relativa e IVI = índice de valor de importância.

\section{REFERÊNCIAS}

AMBIENTE BRASIL. Disponível em: <http://www.guiaflorestal.com.br/ ?pg=lerartigo\&id=83>. Acesso em: 13 maio, 2009.

BIANCO, S. et al. Estimativa da área foliar de Sida cordifolia e Sida rhombifolia usando dimensões satélites do limbo foliar. Planta Daninha, v.26, n.4, p.807-813, 2008. Disponível em: $<$ http://www.scielo.br/scielo.php?script=sci_arttext\&pid=S010083582008000400012>. Acesso em: 02 jun. 2011.

CARON, B.O. et al. Influência da temperatura do ar e radiação solar no acúmulo de fitomassa da alface. Revista Brasileira de Agrometeorologia, v.11, n.2, p.275-283, 2003. Disponível em: <http://www.scielo.br/scieloOrg/php/reflinks.php?refpid=S0100$916200900030000300013 \& \mathrm{p} \mathrm{i} \mathrm{d=S} 0100$ $69162009000300003 \& \operatorname{lng}=\mathrm{em}>$. Acesso em: 05 out. 2009.

CARVALHO, P.E.R. Espécies arbóreas brasileiras. Colombo: Embrapa Florestas, 2003. 1.039p.

KISSMANN, K.G.; GROTH, D. Plantas infestantes e nocivas. São Paulo: BASF, 2000. 2v.

MARCHI, S.R. et al. Efeito de períodos de convivência e de controle das plantas daninhas na cultura de Eucalyptus grandis. In: SEMINÁRIO SOBRE CULTIVO MÍNIMO DO SOLO EM FLORESTAS, 1995, Curitiba, PR. Anais... Curitiba: CNPFloresta/ IPEF/ UNESP/ SIF/ FUPEF, 1995. p.122-133.

MUELlER-DOMbois, D.; EllenberG, H.A. Aims and methods of vegetation ecology. New York: John Wiley, 1974. $547 \mathrm{p}$.

PILAU, F.G. Saldo de radiação da copa de laranjeira num pomar e de renques de cafeeiros: medidas e estimativas. 2005. 92f. Tese (Doutorado em Agronomia) - ESALQ, Piracicaba, SP.

PITELLI, R.A.; MARCHI, S.R. Interferência das plantas daninhas nas áreas de reflorestamento. In: SEMINÁRIO
TÉCNICO SOBRE PLANTAS DANINHAS E O USO DE HERBICIDAS EM REFLORESTAMENTO, 3., 1991, Belo Horizonte, MG. Anais... Belo Horizonte: SIF, 1991. p.1-11.

SAS LEARNING EDITION. Getting started with the SAS learning edition. Cary, 2003. 200p.

SCHNEIDER, P.R. et al. Produção de madeira e casca verde por índice de sítio e espaçamento inicial de Acácia-negra (Acacia mearnsii De Wild). Ciência Florestal, v.11, n.1, p.151-165, 2001. Disponível em: <http://redalyc.uaemex.mx/pdf/534/ 53411113.pdf>. Acesso em: 05 out. 2009.

SILVA, K.R. et al. Custos e rendimentos operacionais de um plantio de eucalipto em Região de cerrado. Revista Árvore, v.28, n.3, p.361-366, 2004. Disponível em: <http:// www.scielo.br/pdf/rarv/v28n3/21602.pdf >. Acesso em: 02 jun. 2011.

TAROUCO, C.P. Períodos de competição de plantas daninhas e seletividade de herbicidas à cultura do eucalipto. 2008. 88f. Dissertação (Mestrado em Agronomia) - Universidade Federal de Pelotas, Pelotas, RS.

TAROUCO, C.P. et al. Períodos de interferência de plantas daninhas na fase inicial de crescimento do eucalipto. Pesquisa Agropecuária Brasileira, v.44, n.9, p.1131-1137, 2009. Disponível em: <http://www.scielo.br/pdf/pab/v44n9/ v44n9a10.pdf>. Acesso em: 02 jun. 2011.

TOLEDO, R.E.B. Faixas de controle de plantas daninhas e seus reflexos no crescimento de plantas de eucalipto. Scientia Forestalis, v.64, p.78-92, 2003. Disponível em: <http:// www.ipef.br/publicacoes/scientia/nr64/cap07.pdf $>$. Acesso em: 05 out. 2009.

TUFFI SANTOS, L.D. et al. Crescimento do eucalipto sob efeito da deriva de glyphosate. Planta Daninha, v.25, n.1, p.133-137, 2007. Disponível em: <http://www.scielo.br/scielo. php?script $=$ sciarttext \&pid $=$ S0100-83582007000100014 >. Acesso em: 02 jun. 2011. 